\title{
Preface
}

This is a companion to our Changing Face of Economics book (Colander et al., 2004a). In our previous book we interviewed top economists at the cutting edge of the profession, who through their work and stories explained to us how the economics profession is changing. What came out in the interviews is that neoclassical economics is no longer the mainstream orthodoxy, and modern economists are exploring a much wider set of issues with a wider set of assumptions than past economists.

As we looked more deeply into who was doing cutting edge work in economics, we recognized that a lot of this important work was taking place in Europe. But for geographical reasons (the three of us teach in America) our previous book focused primarily on interviewing economists in the United States. To make amends, and to continue what had become an enjoyable and informative interviewing process, we decided that it would be fun to supplement that book with interviews of cutting edge economists in Europe. Our thought at that time was the following: we would make the same general arguments about the changing face of modern economics that we made before, but we would replace the United States interviewees with European-based economists.

It did not end up that way. Once we started exploring European economics and talking to European economists in preparation for the project, we found another story going on that was just as important and interesting as the changing face of economics. The other story was that as economics was changing, the European economics academic structure was simultaneously changing in rather substantial ways. What makes this interesting is that the two changes are, in many ways, working against one another. The changes in the European economics profession are reducing the incentives of European economists to do the very work that we describe as cutting edge. It isn't that the top elite in Europe don't value cutting edge work. It's just that they are so concerned with "catching up" with the United States in quantitative measures of research output that they are blinding themselves to the fact that much of the standard work is, at best, pedestrian. All this does is undermine the strengths of European economics by trying to create incentives to "catch up" with the United States on criteria that are backward-looking rather than forwardlooking. They are overemphasizing quality-weighted journal articles and 
losing sight of creative and exciting new ideas that emerge from cutting edge work.

The use of such backward-looking measures is a vice that many of the second tier graduate programs in the United States have fallen into, which essentially makes the work that comes out of these places of little interest in a study of cutting edge work. The main problem with using quantity-weighted measures is that they are not an efficient way of measuring important cutting edge research. By its very nature, cutting edge research often won't get published in the top journals until it has gone through an evolutionary process and been gradually accepted by the profession. Truly new ideas need to go through a period of incubation and then development. It is true that much of the creative work will fail. But the couple of ideas that catch on are what will change economics not the pedestrian work that often shows up in the journals, even the top journals.

In our view, what is important is having an environment that supports such a process. From our previous contacts with European economists, we believed that the European academic institutional structure, for all its many faults, was supporting such a process better than the United States system and that it recognized and appreciated the importance of plurality in economics, which allows the exploration of a wider range of issues. What we found instead was cutting edge work being undermined by institutional changes associated with expansion of the European Union. They were killing the wildflowers to plant a single hayseed, and in doing so were creating a monoculture. They were planting, row after row, acre by acre, a standard variety of flowers found in the United States.

Our strong reaction against this institutional change led us to change the focus of the book to include a discussion about how these excessive concerns about backward-looking research measures were undermining creativity in research.

\section{THE EVOLUTION OF THE BOOK}

Our first task was to get our ideas down. Dave, who had been working on a related project (Colander, 2009), took the lead in coming up with some rough ideas about what was happening in the European economics profession. Barkley, who had been working on histories of economic thought of the various European countries as part of his studies of comparative systems, took the lead in writing about the different traditions. Ric took the lead in drafting a chapter summarizing our views on the changing face of economics in Europe and also worked hard to blend Dave and 
Barkley's ideas together (no easy task). Eventually, after much toing and froing, rewrites and further rewrites, we ended up with Chapters 1 and 2.

Once we had these chapters we decided whom to interview. Barkley took the lead in setting up the interviews, and he and Ric made a trip to Europe to start the process. Over the next year further interviews were done, a number of them at a conference that Barkley organized as part of a symposium on complexity for the Journal of Economics and Behavioral Organization at James Madison University. We transcribed the interviews, and sent them back to the interviewees, leaving them free to modify them as they saw fit. Finally we decided that we wanted some wise and excellent economists to reflect on the overall project and the future of European economics. We thought János Kornai and Reinhard Selten would be perfect to do that. They both graciously agreed. Since Barkley was going over again to Europe with his wife, Marina Rosser, who is a top economist, they both interviewed Professors Kornai and Selten for this book. These are not the only interviews that Marina was part of. She also participated in the Geoff Hodgson interview. In many ways she should be considered a fourth author.

A note about the order of our names as authors: given our friendship and professional respect for each other we rotate our names with each new book that we do together. 
J. Barkley Rosser Jr, Richard P.F. Holt, and David Colander - 9781849805544 Downloaded from PubFactory at 04/26/2023 09:43:34AM 